\section{G. Vaiopoulos \\ P. P. Sfikakis \\ E. Velikas \\ C. Kittas \\ P. Kaklamanis}

\title{
Tuberculosis of the sacroiliac joint
}

Abstract A 23-year-old woman presented with low back pain of several months' duration. A tuberculous infection of the left sacroiliac joint was diagnosed by closed-needle biopsy. The clinical presentation, radiologi- cal features and outcome of this patient are discussed.

Key words Tuberculosis . Sacroiliac joint - Conservative treatment $\cdot$ Needle biopsy

First Department of Internal Medicine,

University of Athens Medical School,

Laiko General Hospital,

17 Agiou Thoma Street,

Goudi, Athens GR 115 27, Greece

Fax +30-1-7771161

\section{P. P. Sfikakis}

First Propedeutiki Medical Department, University of Athens Medical School,

Laiko General Hospital, Athens, Greece

\section{E. Velikas}

Department of Orthopaedics,

General Hospital of Piraeus,

Piraeus, Greece

\section{Kittas}

Department of Histology,

University of Athens Medical School,

Laiko General Hospital, Athens, Greece

\section{Introduction}

Tuberculosis is nowadays not a rare disease. It is estimated that 1 billion persons worldwide are infected with Mycobacterium tuberculosis [2]. Tuberculosis has thus not been eradicated [4] and recently an outbreak was reported [8]. Extrapulmonary involvement is present in $18 \%$ of the cases reported in the United States [2] and pleurisy is frequently caused by reactivation of the disease [1].

We report a patient with tuberculosis of the sacroiliac joint. The diagnosis was established by finding granuloma and acid fast bacilli in the specimen of the joint.

\section{Case report}

A 23-year-old Greek woman, a lawyer, presented with a 14-month history of low back pain. She had been treated with non-steroidal anti-infammatory drugs without any success. The pain had recently worsened and resulted in difficulty in working. There was no fever, weight loss or other constitutional symptom. On admission, her temperature was $36.8^{\circ} \mathrm{C}$, her pulse was $70 / \mathrm{min}$ and her blood pressure $120 / 80 \mathrm{~mm} \mathrm{Hg}$. Physical examination revealed mild tenderness over the left sacroiliac joint. Neurological examination revealed no abnormalities. Laboratory examination showed mild anaemia, an ESR of $82 \mathrm{~mm} / \mathrm{h}$ and a C-reactive protein of 95 $\mathrm{mg} / \mathrm{dl}$ (normal $<5 \mathrm{mg} / \mathrm{dl}$ ). Tuberculin skin test was positive $(15$ $\mathrm{mm}$ ). Results of biochemical investigation were normal or negative. Chest radiographs showed clear lungs. Pelvic radiograph showed a widening and rarefaction of the upper left of the sacroiliac joint. A CT scan revealed erosions of the left sacroiliac joint (Fig. 1). A ${ }^{90 \mathrm{~m} T \mathrm{~T}}$ methylene diphosphonate radionucline bone scan revealed increased uptake on the left side of the sacrum. A needle 


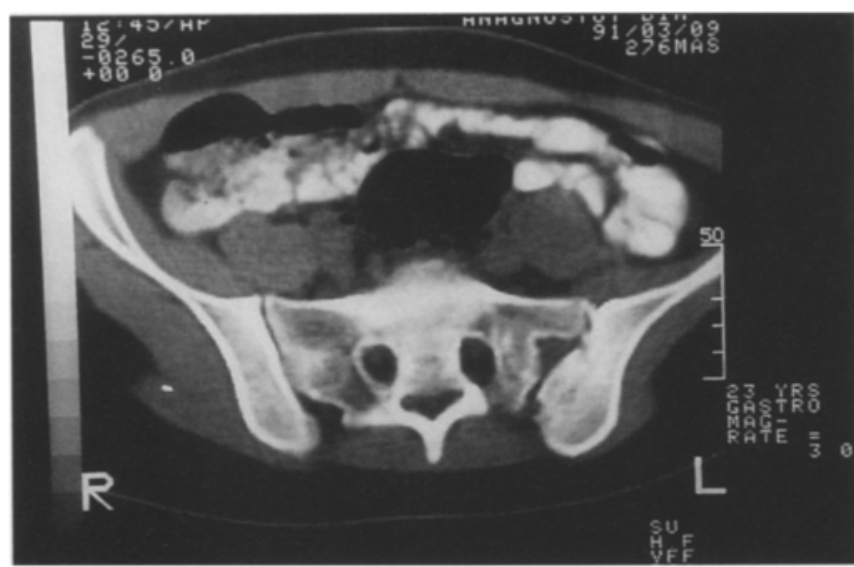

Fig. 1 CT scan demonstrated erosion of the left sacroiliac joint

biopsy of the area was performed and a granuloma with caseous necrosis, some Langhans multinucleated giant cells and acid fast micro-organisms were observed. A combination therapy was administered, consisting of dianicotyl $400 \mathrm{mg} /$ day, rifampicin 600 $\mathrm{mg} /$ day and myambutal $1200 \mathrm{mg} / \mathrm{day}$. T.wo months later there were no laboratory or clinical findings. A year later plain radiographs demonstrated density of the left side of the sacroiliac joint.

\section{Discussion}

Sacroiliac tuberculosis is a rare condition and is difficult to assess $[10,12]$, although, recently, new cases of sacroiliac tuberculosis have been published, emphasizing the newer diagnostic procedures and the differential diagnosis $[3,11]$. Tuberculosis of bone usually follows primary infection. The mycobacteria spread haematogenously at the time of the primary infection or, later, from a dormant primary site or from another extraosseous secondary focus [13]. In our patient we could not find the primary site and the only finding was the positive tuberculin test [9]. Although the tuberculin skin test is the only method of detecting $M$. tuberculosis infection, it is neither $100 \%$ sensitive nor $100 \%$ specific [7]. Pelvic radiographs, bone scans and CT scan showed a localized lesion at the left sacroiliac joint. These methods of investigation give satisfactory results in the majority of patients with inflammatory disease $[6,12]$, although they do not have the sensitivity to differentiate pyogenic from granulomatous sacroiliitis [5]. Therefore, in view of the laboratory findings, the positive tuberculin skin test, the lack of evidence of any underlying seronegative spondyloarthropathy and the CT scan findings, a needle biopsy was carried out and histological findings confirmed the diagnosis. Therefore, biopsy of the joint is necessary for the diagnosis [12]. In addition, the results of the treatment supported the diagnosis in our patient.

\section{References}

1. Antoniskis D, Amin K, Barnes PF (1990) Pleuritis as a manifestation of reactivation tuberculosis. Am J Med 89: 447-450

2. Bloch AB, Rieder HL, Kelly GD, Couthen GM, Hayden CH, Snider DE (1989) The epidemiology of tuberculosis in the United States. Implications for diagnosis and treatment. Clin Chest Med 10: 237-313

3. Chen WS (1995) Chronic sciatica caused by tuberculous sacroiliitis: a case report. Spine 20: 1194-1196

4. Davies PDO, Humphries MJ, Byfield SP, et al (1984) Bone and joint tuberculosis. A survey of notifications in England and Wales. J Bone Joint Surg [Br] 66: 326-330

5. Gordon J, Kabins SA (1980) Pyogenic sacroiliitis. Am J Med 69: 50-56
6. Horgan JD, Walker M, Newman JH, Watt I (1982) Scintigraphy in the diagnosis and management of septic sacroiliitis. Clin Radiol 34: 337

7. Huebner RE, Schein MF, Bass JB (1993) The tuberculin skin test. Clin Infect Dis 17: 968-975

8. Kline SE, Hedemark LL, Davies SF (1995) Outbreak of tuberculosis among regular patrons of a neighborhood bar. N Engl J Med 333: 222-227

9. Lifeso RM, Weaver P, Harder EH (1985) Tuberculous spondylitis in adults. J Bone Joint Surg [Am] 67: 1405-1414

10. Nicolson RA (1974) Twenty years of bone and joint tuberculosis in Bradford. A comparison of the disease in the indigenous and Asian populations. J Bone Joint Surg [Br] 56: 760-765
11. Osman AA, Shunmugam G (1995) Septic sacroiliitis. Clin Orthop 313: 214-219

12. Pouchot J, Viceneux P, Varge J (1988) Tuberculosis of the sacroiliac joint: clinical features, outcome and evaluation of closed needle biopsy in 11 consecutive cases. Am J Med 64: 622-628

13. Resnick D, Niwayama G (1981) Osteomyelitis, septic arthritis, and soft tissue infection: the mechanisms and situations. In: Resnick D, Niwayama G (eds) Diagnosis of bone and joint disorders with emphasis on articular abnormalities, vol 3. Saunders, Philadelphia, pp 2042-2129 